Psychological Medicine, 1998, 28, 1007-1013. Printed in the United Kingdom

(C) 1998 Cambridge University Press

\title{
EDITORIAL
}

\section{Late-onset depressive disorders: a preventable variant of cerebrovascular disease ${ }^{1}$}

The severe depressive disorders of late life are associated with high rates of medical morbidity and mortality, cognitive impairment, suicide, disability, complex treatment regimens, institutionalization and high costs to the community (Murphy, 1983; Murphy et al. 1988; Bruce \& Leaf, 1989; NIH Consensus Development Panel, 1992; Alexopoulos et al. $1993 a$, b; Brodaty et al. 1993; Bruce et al. 1994; Forsell et al. 1994; Hickie et al. 1995; Blazer, 1996). Those disorders that are accompanied by cognitive impairment and/or concurrent medical morbidity have a particularly poor outcome (Bruce \& Leaf, 1989; Alexopoulos et al. 1993 b; Hickie et al. 1995, 1997a). Although psychosocial models of late-life depression place considerable importance on age-related psychological and social risk factors, those who survive into later life may actually be characterized by psychological resilience (Henderson, 1994; Blazer, 1997).

Current aetiological research in late-life depression, therefore, places particular emphasis on the potential role of biological risk factors. The potential importance of vascular risk factors is receiving renewed attention and may provide opportunities for specific prevention and intervention strategies in high-risk populations. This emphasis on possible vascular risk factors, and the wider importance of vascular pathologies in late-life neuropsychiatric disorders, mirrors the emphasis of much earlier clinico-pathological studies (Binswanger, 1894; Alzheimer, 1895). The specific focus on the importance of small progressive changes within the subcortical white matter, as distinct from more discrete cortical infarcts (Olszewski, 1962), is now supported by the emerging neuroimaging literature and theoretical constructs in late-life depression (Krishnan, 1991, 1993; Hickie et al. 1996, 1997 b; Krishnan et al. 1997).

\section{IDENTIFYING RISK FACTORS FOR LATE-LIFE DEPRESSION}

Clinical and neuroimaging studies in late-life depression now highlight the relevance of current age and age of onset (Coffey et al. 1990; Krishnan, 1991, 1993; Alexopoulos et al. 1993 a; Krishnan et al. 1995; Hickie et al. 1995, 1996; Brodaty, 1996). The validity of the proposed distinction between early-onset (typically less than 50 years) and late-onset primary depressive disorders is being tested against clinical features, neurobiological correlates, genetic and biochemical risk factors, treatment response and longitudinal course. Phenomenologically, a subgroup of older patients with severe depression is characterized by severe psychomotor change, psychotic features and cognitive impairment (Brodaty et al. 1991; Brodaty, 1996). However, few clinical differences exist between those older patients who have either the early-onset or late-onset subtype (Alexopoulos et al. 1988; Alexopoulos, 1990; Krishnan et al. 1995; Brodaty, 1996), indicating that if age-associated risk factors are operative they cannot be identified simply by specific clinical features. As the familial risk to depression declines with age of onset (Mendlewicz, 1976; Mendlewicz \& Baron, 1981), late-onset disorders are also more likely to be a consequence of pathologies whose incidence increases with age, such as neurodegenerative and vascular diseases. Therefore, non-clinical strategies such as neuroimaging, biochemical studies or genetic screening may be necessary to detect these ageassociated pathogenic processes.

\footnotetext{
${ }^{1}$ Address for correspondence: Professor Ian Hickie, Academic Department of Psychiatry, St George Hospital \& Community Health Service, 7 Chapel Street, Kogarah, NSW 2217, Australia.
} 


\section{DEPRESSION AND DEMENTIA SYNDROMES}

Older patients with severe depression often present with pronounced cognitive impairment, the socalled 'dementia of depression' syndrome (Folstein \& McHugh, 1978; Alexopoulos et al. 1993 b). Although traditionally classed as 'pseudodementias' (Kiloh, 1981), longitudinal studies demonstrate that a significant subproportion do develop irreversible cognitive impairment, chronic depression and residual disability (Alexopoulos et al. 1993 b; Hickie et al. 1997 a). Major depression does not appear to be a central feature of dementia of the Alzheimer type (Brodaty \& Luscombe, 1996) and when depressive symptoms do occur during the course of a primary dementia syndrome, it is likely that the dementia has a vascular aetiology (Ballard et al. 1996). Longitudinal studies emphasize the medical morbidity and mortality experienced by patients with depressive disorders, particularly in older patients, where cardiovascular and cerebrovascular diseases are important (Hickie et al. 1993; Bruce et al. 1994).

Overt cerebrovascular disease, including stroke, is particularly associated with increased rates of affective disorder (Robinson et al. 1984, 1988). Longer-term studies also suggest that depressed patients may be at increased risk of dementia, and that such dementias are likely to be of the vascular type (Luscombe et al. 1995; Hickie et al. 1997a). Importantly, recent epidemiological evidence confirms that hypertension is a risk factor to dementia (Skoog et al. 1996), probably due to disruption of cortical-subcortical paths. Patients with cognitive impairment are also at increased risk of later overt stroke, suggesting that cerebrovascular disease plays a larger role in the aetiology of late-onset dementias than previously suspected (Ferrucci et al. 1996).

\section{MAGNETIC RESONANCE IMAGING (MRI) IN LATE-LIFE DEPRESSION}

Magnetic resonance imaging (MRI) studies demonstrate that older patients with severe depression have a range of abnormalities including loss of cerebral volume with preferential reduction in frontal cortex, increased lateral ventricular size, reduction in the volume of the caudate and putamen nuclei, and an increased prevalence of extensive subcortical white matter hyperintensities (SWMHs) (Coffey et al. 1988, 1989, 1990, 1993; Krishnan et al. 1988, 1992, 1997; Figiel et al. 1991; Hussain et al. 1991; Brown et al. 1992; Krishnan, 1993; Fujikawa et al. 1994; Hickie et al. 1995; Greenwald et al. 1996; O’Brien et al. 1996; Kumar et al. 1997; Simpson et al. 1997). These studies suggest that relevant risk factors for extensive SWMHs are: a diagnosis of depression; older age; older age of onset; risk factors to cerebrovascular disease (notably hypertension and diabetes); treatment-resistance; and, concurrent medical morbidity. Consistent with the notion of late-onset disorders resulting from age-related pathologies, patients with extensive SWMHs do not have increased family histories of affective disorder (Hickie et al. 1995; Krishnan et al. 1997). Similar subcortical changes on MRI have been reported in other neurodegenerative disorders, notably Alzheimer's disease (AD), but the prevalence of extensive lesions within the deep white matter is clearly increased relative to age-matched controls only in patients with depression and/or those with concurrent vascular risk factors (Fazekas et al. 1987; Brown et al. 1992; Kumar et al. 1992; Erkinjuntti et al. 1994; O'Brien et al. 1996).

While the pathological significance of SWMHs on MRI was initially debated, histopathological studies suggest that small lesions represent vascular ectasia and expansion of perivascular spaces (i.e. non-pathological age-related changes), while larger punctate and more diffuse lesions involve demyelination of axons, axonal degeneration, proliferation of oligodendroglial cells, the presence of occasional macrophages (consistent with tissue damage) and, less frequently, discrete microinfarction (Awad et al. 1986; Braffman et al. 1988; Marshall et al. 1988; Fazekas et al. 1993; Scheltens et al. 1995). The deep white matter is particularly susceptible to such degenerative changes as it is perfused by small perforating arterioles that are prone to the adverse long-term effects of hypertension and diabetes. The neuropathological changes suggest a spectrum of vascular impairment ranging from chronic hypoperfusion to episodes of 'neurologically-silent' microinfarction and, eventually, widespread subcortical leucoencephalopathy ('Binswanger's disease'). 
Periventricular changes, however, appear to be a consequence of breakdown in the ventricular ependyma, with leakage of cerebrospinal fluid into the white matter.

The clinical significance of extensive SWMHs in late-life depression has become increasingly apparent. Extensive SWMHs are associated with psychomotor slowing and a pattern of 'subcortical' rather than 'cortical' neuropsychological impairment in normal older subjects (Ylikoski et al. 1993), patients with vascular risk factors (Junque et al. 1990) and patients with depression (Hickie et al. 1995; Hickie, 1996; Lesser et al. 1996; Salloway et al. 1996). SWMHs predict delirium in response to antidepressant therapies (Figiel et al. 1991), a poorer clinical response to standard treatment regimens, including ECT (Hickie et al. 1995), and a poorer longitudinal course with high rates of residual disability and institutionalization (Hickie et al. 1997a). Importantly, in a significant minority of patients, extensive SWMHs predict the development of irreversible cognitive impairment consistent with a vascular aetiology (Hickie et al. $1997 a)$.

\section{IDENTIFYING GENETICALLY-DETERMINED RISK FACTORS}

The identification of the $\epsilon 4$ isoform of apolipoprotein E (Apo E) as a risk factor for AD (Saunders et al. $1993 a, b$ ) has intensified the search for other genetic and biochemical risk factors which may predispose to late-onset neuropsychiatric disorders. While genetic factors appear to play a large role in determining the risk to $\mathrm{AD}$, environmental factors and specific gene-environment interactions (e.g. smoking, dietary behaviours) appear to be much more relevant to vascular dementia (Bergem et al. 1997; Plassman \& Breitner, 1997). Hence, identification of relevant genetic and environmental risk factors may provide the basis for highly-targeted preventative strategies.

Apo E $\epsilon 4$ also has an atherogenic effect due to elevation of circulating levels of low-density lipoproteins (Davignon et al. 1988), and possibly via an effect on the response of the vessel wall to injury (Vogel et al. 1994; Wang et al. 1995). Increased rates of the Apo E $\epsilon 4$ isoform have been detected in some studies of patients with vascular dementia (Shimano et al. 1989; Pedro-Botet et al. 1992; Noguchi et al. 1993; Frisoni et al. 1994), but not others (Betard et al. 1994; Kawamata et al. 1994; Sakoda et al. 1994). Most importantly, the Apo $\epsilon 4$ isoform has also been detected with increased frequency in a small group of patients with late-life depression (Krishnan et al. 1994). Given its role in atherogenesis, and its involvement in central nervous system response to injury (Ignatius et al. 1987; Goedert et al. 1994), it is likely that Apo E $\epsilon 4$ is not simply a risk factor to late-onset $\mathrm{AD}$, but rather a risk factor to a wider range of pathologies which cause primary (e.g. $\mathrm{AD})$ or secondary (e.g. via vascular effects) damage to neural tissue.

The evidence with regard to the vascular risks associated with Apo $\mathrm{E} \epsilon 2$ isoform is less clear. Apo $\mathrm{E}$ $\epsilon 2$ has been consistently associated with raised triglyceride levels (Davignon et al. 1988), and has been associated with vascular dementia (Betard et al. 1994). More recently, it has been suggested that Apo E $\epsilon 2$ may be a protective factor against the severity of vascular disease (Wang et al. 1995). It has been suggested that Apo E $\epsilon 2$ is specifically associated with depressive symptomatology in late-onset AD (Holmes et al. 1996).

Elevations in levels of serum homocysteine have been consistently demonstrated in patients with coronary and cerebrovascular disease, while discrete hyperhomocysteinaemia has been associated with increased risk for both myocardial infarction and stroke (Wilcken et al. 1983; Ueland et al. 1992; Boers, 1994). Although a variety of conditions may result in raised homocysteine, the link with vascular disease appears to remain constant. Genetically-determined differences in the enzyme 5, 10-methylenetetrahydrofolate reductase (MTHFR) result in elevated levels of homocysteine and these have been associated with early-onset vascular disorders. Potentially, polymorphisms in the MTHFR gene may serve as markers for those at risk of vascular disease (Wilcken et al. 1996).

Folate and vitamins $B_{12}$ and $B_{6}$ play a key role in homocysteine metabolism and dietary deficiency of folic acid has been associated with hyperhomocysteinaemia and atherogenesis (Selhub et al. 1995). It is possible that low or marginal levels of vitamins $B_{12}$ and $B_{6}$ and/or serum folate may interact with minor, common enzymatic differences to increase the risk of vascular disease (Wilcken 
et al. 1996). As many older persons have inadequate dietary consumption of folate and raised homocysteine, they may be at particular risk of vascular disease (Selhub et al. 1993). While the use of folate and vitamin B supplements as a preventive strategy for vascular disease awaits larger-scale replication, the possibility that such simple interventions might ameliorate the progression of cerebrovascular disease is an attractive proposition.

\section{REDEFINING LATE-LIFE DEPRESSIONS}

Advances in general medicine create opportunities for strategic research in neuropsychiatry. In the future, depressive subtypes may be defined by combinations of neurobiological features and risk factors rather than clinical features. For example, Krishnan et al. (1997) have recently proposed the term 'vascular depression' to identify depressed patients with concurrent deep white matter or subcortical grey matter hyperintensities on MRI. The validity of this notion is supported not only by clinical validators such as older age, later age of onset and a reduced familial rate of mental illness (Krishnan et al. 1997), but also by functional imaging studies which demonstrate reduced cerebral perfusion in patients with extensive white matter changes (Lesser et al. 1994). Krishnan et al. (1994) had earlier proposed another depressive subtype characterized by late-onset, cognitive impairment and presence of the Apo E $\epsilon 4$ allele. The validity of this proposed subgroup can be tested longitudinally by studying rates of progression to dementia.

As a narrower clinico-pathological entity, we have described a more restrictive depressive subtype (Hickie et al. 1995, 1996, 1997a). We emphasize the presence of observable psychomotor change, subcortical neuropsychological signs, late-onset, reduced familial rates of depression, treatmentresistance, vascular risk factors and subcortical MRI changes. Longitudinal studies support the validity of this subtype by demonstrating increased adverse effects from physical treatments, impaired response to antidepressant therapy and progression to chronic depression and dementia of the vascular type (Figiel et al. 1991; Hickie et al. 1995, 1997a).

Such longitudinal cohort studies, which combine relevant clinical, neurobiological, imaging and genetic factors, have the capacity to advance rapidly our understanding of the pathophysiology of these disorders. Concurrently, broader epidemiological studies are now required to determine whether hypertension, or any of the genetic risk factors to AD or vascular disease, are populationbased risk factors to late-onset depression. As has been demonstrated with non-steroidal antiinflammatory agents in AD (Breitner et al. 1994), such focused epidemiological studies also have the capacity to detect potential protective factors. Following such studies, it should be possible to create more exact criteria sets and/or diagnostic instruments, based on combinations of key clinical and laboratory features, which identify more specific pathophysiological entities.

\section{PREVENTION OF LATE-ONSET DEPRESSION}

If some severe late-onset depressions are actually sequelae of impaired subcortical perfusion then there is considerable scope for both primary and secondary prevention. The public health emphasis on modification of risk factors to cerebrovascular disease (Hachinski, 1992) may lead eventually to lower incidence rates of late-onset depression. Furthermore, the rapidly expanding knowledge of specific genetic risk factors to vascular disease and/or neurodegenerative processes may help to focus primary prevention strategies on high-risk populations. Adequate evaluation of vascular risk factors should also be incorporated into the clinical assessment of patients with late-onset depression, as progression of an underlying vascular pathophysiology appears to increase the rate of disability, institutionalization and progression to vascular-type dementia (Hickie et al. 1997a). Standard clinical features (smoking history, blood pressure, diabetes) may need to be augmented by pursuit of relevant dietary history and laboratory (e.g. serum folate, homocysteine, presence of antiphospholipid antibodies) features. Modification of known risk factors to cerebrovascular disease in patients with late-onset depression, in addition to simple interventions such as folate and 
vitamin B supplementation, may help to reduce the rate of disease progression, improve longitudinal course and reduce the rate of progressive cognitive impairment.

IAN HICKIE AND ELIZABETH SCOTT

This project has been supported by the National Health and Medical Research Council of Australia (Program Grant No. 953208). Dr Elizabeth Scott was supported by a Research Fellowship from the NSW Institute of Psychiatry. Extensive editorial assistance was provided by Cristina Ricci.

\section{REFERENCES}

Alexopoulos, G. S. (1990). Clinical and biological findings in lateonset depression. In Review of Psychiatry (ed. A. Tassman, S. M. Goldfinger and C. A. Kaufman), vol. 9, pp. 249-262. APA Press: Washington, DC.

Alexopoulos, G. S., Young, R. C., Meyers, B. S., Abrams, R. C. \& Shamoian, C. A. (1988). Late-onset depression. Psychiatric Clinics of North America 11, 101-115.

Alexopoulos, G. S., Young, R. C. \& Meyers, B. S. (1993a). Geriatric depression: age of onset and dementia. Biological Psychiatry 34, 141-145.

Alexopoulos, G. S., Meyers, B. S., Young, R. C., Mattis, S. \& Kakuma, T. (1993b). The course of geriatric depression with 'reversible dementia': a controlled study. American Journal of Psychiatry 150, 1693-1699.

Alzheimer, A. (1895). Die arteriosklerotische Atrophie des Gehirns. Allgemeine Zeitschrift für Psychiatrie 51, 809-811. (Translated and reprinted as: Alzheimer, A. (1991). Arteriosclerotic brain atrophy. International Journal of Geriatric Psychiatry 6, 129-130.)

Awad, I. A., Johnson, P. C., Spetzler, R. F. \& Hodak, J. A. (1986). Incidental subcortical lesions identified on magnetic resonance imaging in the elderly. II. Postmortem pathological correlations Stroke 17, 1090-1097.

Ballard, C. G., Patel, A., Solis, M., Lowe, K. \& Wilcock, G. (1996) A one-year follow-up study of depression in dementia suffers. British Journal of Psychiatry 168, 287-291.

Bergem, A. L. M., Engedal, K. \& Kringlen, E. (1997). The role of heredity in late-onset Alzheimer disease and vascular dementia. Archives of General Psychiatry 54, 264-270.

Betard, C., Robitaille, Y., Gee, M., Tiberghien, D., Larrivee, D., Roy, P., Mortimer, J. A. \& Gauvreau, D. (1994). Apo E allele frequencies in Alzheimer's disease, Lewy body dementia, Alzheimer's disease with cerebrovascular disease and vascular dementia. Neuroreport 5, 1893-1896.

Binswanger, O. (1894). Die Abgrenzung der allgemeinen progressiven Paralyse. Berliner Klinische Wochenshrift 31, 1137-1139.

Blazer, D. (1996). The danger of reducing reimbursement for psychiatric disorders in late life. American Journal of Psychiatry 153, 857-859.

Blazer, D. G. (1997). Depression in the elderly: myths and misconceptions. Psychiatric Clinics of North America 20, 111-119.

Boers, G. H. (1994). Hyperhomocysteinaemia: a newly recognized risk factor for vascular disease. Netherlands Journal of Medicine 45, 34- 41 .

Braffman, B. H., Zimmerman, R. A., Trojanowski, J. Q., Gonatas, N. K., Hickey, W. F. \& Schlaepfer, W. W. (1988). Brain MR: pathologic correlation with gross and histopathology. II. Hyperintense white-matter foci in the elderly. American Journal of Roentgenology 151, 559-566.

Breitner, J. C. S., Gau, B. A., Welsh, K. A., Plassman, B. L., McDonald, W. M., Helms, M. J. \& Anthony, J. C. (1994). Inverse association of anti-inflammatory treatments and Alzheimer's disease: initial results of a co-twin control study. Neurology 44, 227-232.

Brodaty, H. (1996). Melancholia and the ageing brain. In Melancholia: A Disorder of Movement and Mood (ed. G. Parker and D. Hadzi-Pavlovic), pp. 237-251. Cambridge University Press: New York
Brodaty, H. \& Luscombe, G. (1996). Depression in persons with dementia. International Psychogeriatrics 8, 609-622.

Brodaty, H., Peters, K., Boyce, P., Hickie, I., Parker, G., Mitchell, P. \& Wilhelm, K. (1991). Age and depression. Journal of Affective Disorders 23, 137-149.

Brodaty, H., Harris, L., Peters, K., Hickie, I., Boyce, P., Mitchell, P., Parker, G., Wilhelm, K. \& Hadzi-Pavolovic, D. (1993). Prognosis of depression in the elderly. British Journal of Psychiatry 163, 589-596.

Brown, F. W., Lewine, R. J., Hudgins, P. A. \& Risch, S. C. (1992). White matter hyperintensity signals in psychiatric and nonpsychiatric subjects. American Journal of Psychiatry 149, 620-625.

Bruce, M. L. \& Leaf, P. J. (1989). Psychiatric disorders and 15month mortality in a community sample of older adults. American Journal of Public Health 79, 727-730.

Bruce, M. L., Leaf, P. J., Rozal, G. P. M., Florio, L. \& Hoff, R. A. (1994). Psychiatric status and 9-year mortality data in the New Haven Epidemiologic Catchment Area Study. American Journal of Psychiatry 151, 716-721.

Coffey, C. E., Figiel, G. S., Djang, W. T., Cress, M., Saunders, W. B. \& Weiner, R. D. (1988). Leukoencephalopathy in elderly depressed patients referred for ECT. Biological Psychiatry 24, 143-161.

Coffey, C. E., Figiel, G. S., Djang, W. T., Saunders, W. B. \& Weiner, R. D. (1989). White matter hyperintensities on MRI clinical and neuroanatomic correlates in the depressed elderly. Journal of Neuropsychiatry and Clinical Neurosciences 1, 135-144.

Coffey, C. E., Figiel, G. S., Djang, W. T. \& Weiner, R. D. (1990). Subcortical hyperintensity on magnetic resonance imaging: a comparison of normal and depressed elderly subjects. American Journal of Psychiatry 147, 187-189.

Coffey, C. E., Wilkinson, W. E., Weiner, R. D., Parashos, I. A., Djang, W. T., Webb, M. C., Figiel, G. S. \& Spritzer, C. E. (1993). Quantitative cerebral anatomy in depression: a controlled magnetic resonance imaging study. Archives of General Psychiatry 50, 7-16.

Davignon, J., Greeg, R. E. \& Sing, C. F. (1988). Apolipoprotein E polymorphism and atherosclerosis. Arteriosclerosis 8, 1-21.

Erkinjuntti, T., Gao, F., Lee, D. H., Eliasziw, M., Merskey, H. \& Hachinski, V. C. (1994). Lack of difference in brain hyperintensities between patients with early Alzheimer's disease and control subjects. Archives of Neurology 51, 260-268.

Fazekas, F., Chawluk, J. B., Alavi, A., Hurtig, H. I. \& Zimmerman, R. A. (1987). MRI signal abnormalities at 1.5T in Alzheimer's dementia and normal ageing. American Journal of Roentgenology 149, 351-356.

Fazekas, F., Kleinert, R., Offenbacher, H., Schmidt, R., Kleinert, G., Payer, F., Radner, H. \& Lechner, H. (1993). Pathologic correlates of incidental MRI white matter signal hyperintensities. Neurology 43, 1683-1689.

Ferrucci, L., Guralnik, J. M., Salive, M. E., Pahor, M., Corti, M. C., Baroni, A. \& Havlik, R. J. (1996). Cognitive impairment and risk of stroke in the older population. Journal of the American Geriatrics Society 44, 237-241.

Figiel, G. S., Krishnan, K. R. R., Doraiswamy, M., Rao, V. P., Nemeroff, C. B. \& Boyko, O. B. (1991). Subcortical hyperintensities on brain magnetic resonance imaging: a comparison between late age onset and early onset elderly depressed subjects. Neurobiology of Aging 26, 245-247.

Folstein, M. \& McHugh, P. (1978). Dementia syndrome of 
depression. In Alzheimer's Disease: Senile Dementia and Related Disorders: Aging (ed. R. Katzman, R. D. Terry and K. L. Bick), pp. 87-93. Raven Press: New York.

Forsell, Y., Jorm, A. F. \& Winbald, B. (1994). Outcome of depression in demented and non-demented elderly: observations from a threeyear follow-up in a community-based study. International Journal of Geriatric Psychiatry 9, 5-10.

Frisoni, G. B., Calabresi, L., Geroldi, C., Bianchetti, A. D'Acquarica, A. L., Govoni, S., Sirtori, C. R., Trabucchi, M. \& Franceschini, G. (1994). Apolipoprotein E $\epsilon 4$ allele in Alzheimer's disease and vascular dementia. Dementia 5, 240-242.

Fujikawa, T., Yamawaki, S. \& Touhouda, Y. (1994). Background factors and clinical symptoms of major depression with silent cerebral infarction. Stroke 25, 798-801.

Goedert, M., Strittmatter, W. J. \& Roses, A. D. (1994). Risky apolipoprotein in brain. Nature 372, 45-46.

Greenwald, B. S., Kramer-Ginsberg, E., Krishnan, K. R. R., Ashtari, M., Aupperle, P. M. \& Patel, M. (1996). MRI signal hyperintensities in geriatric depression. American Journal of Psychiatry 153, 1212-1215.

Hachinski, V. (1992). Preventable senility: a call for action against the vascular dementias. Lancet 340, 645-648.

Henderson, A. S. (1994). Does aging protect against depression? Social Psychiatry and Psychiatric Epidemiology 29, 107-109.

Hickie, I. (1996). Validity of the CORE. II. Neuropsychological tests. In Melancholia: A Disorder of Movement and Mood (ed. G. Parker and D. Hadzi-Pavlovic), pp. 149-159. Cambridge University Press: New York

Hickie, I., Hickie, C. \& Bennett, B. (1993). Does immune dysfunction in depression cause medical illness? Evaluation of the epidemiological evidence. In Psychoimmunology CNS-Immune Interactions (ed. A. Husband), pp. 65-78. CRC Press: Boca Raton, FL.

Hickie, I., Scott, E., Mitchell, P., Wilhelm, K., Austin, M. P. \& Bennett, B. (1995). Subcortical hyperintensities on magnetic resonance imaging: clinical correlates and prognostic significance in patients with severe depression. Biological Psychiatry 37 , 151-161.

Hickie, I., Hickie, C., Scott, E. \& Wilhelm, K. (1996). Magnetic resonance imaging in primary and secondary depression. In Melancholia: A Disorder of Movement and Mood (ed. G. Parker and D. Hadzi-Pavlovic), pp. 252-266. Cambridge University Press: New York.

Hickie, I., Scott, E., Wilhelm, K. \& Brodaty, H. (1997a). Subcortical hyperintensities on magnetic resonance imaging in patients with severe depression - longitudinal evaluation. Biological Psychiatry 42, 367-374.

Hickie, I., Lloyd, A., Dixon, G., Halliday, G., McRitchie, D., Scott, E., Mitchell, P. \& Wakefield, D. (1997b). Utilising molecular biological and histopathological techniques to study the dopaminergic system in patients with melancholia. Australian and New Zealand Journal of Psychiatry 31, 27-35.

Holmes, C., Levy, R., McLoughlin, D. M., Powell, J. F. \& Lovestone, S. (1996). Apolipoprotein E: non-cognitive symptoms and cognitive decline in late onset Alzheimer's disease. Journal of Neurology, Neurosurgery and Psychiatry 61, 580-583.

Husain, M. M., McDonald, W. M., Doraiswamy, P. M., Figiel, G. S., Na, C., Escalona, P. R., Boyko, O. B., Nemeroff, C. B. \& Krishnan, K. R. (1991). A magnetic resonance imaging study of putamen nuclei in major depression. Psychiatry Research 40, 95-99.

Ignatius, M. J., Schooter, E. M., Pitas, R. E. \& Mahley, R. W. (1987). Lipoprotein uptake by neuronal growth cones in vitro. Science 236, 959-962.

Junque, C., Pujol, J., Vendrell, P., Bruna, O., Jodar, M., Ribas, J. C., Vinas, J., Capdevilla, A. \& Marti-Vilalta, J. L. (1990). Leukoaraiosis on magnetic resonance imaging and speed of mental processing. Archives of Neurology 47, 1127-1133.

Kawamata, J., Tanaka, S., Shimohama, S., Ueda, K. \& Kimura, J. (1994). Apolipoprotein E polymorphism in Japanese patients with Alzheimer's disease or vascular dementia. Journal of Neurology, Neurosurgery and Psychiatry 57, 1414-1416.
Kiloh, L. G. (1981). Depressive illness masquerading as dementia in the elderly. Medical Journal of Australia 2, 550-553.

Krishnan, K. R. R. (1991). Organic base of depression in the elderly. Annual Review of Medicine 42, 261-266.

Krishnan, K. R. R. (1993). Neuroanatomic substrates of depression in the elderly. Journal of Geriatric Psychiatry and Neurology $\mathbf{6}$, $39-58$.

Krishnan, K. R. R., Goli, V., Ellinwood, E. H., France, R. D., Blazer, D. G. \& Nemeroff, C. B. (1988). Leukoencephalopathy in patients diagnosed as major depressive. Biological Psychiatry 23, 519-522.

Krishnan, K. R. R., McDonald, W. M., Escalona, P. R., Localona, P. R., Doraiswamy, L. A., Na, C., Husain, M. M., Figiel, G. S., Boyko, O. B., Ellinwood, E. H. \& Nemeroff, C. B. (1992). Magnetic resonance imaging of the caudate nuclei in depression: preliminary observations. Archives of General Psychiatry 49, 553-557.

Krishnan, K. R. R., Ritchie, J. C., Tupler, L. A., McDonald, W. M., Knight, D., Nancroff, C. B. \& Marcovinch, S. (1994). Apolipoprotein E- $\epsilon 4$ - Reply (correspondence). Neurology 44, 2420-2421.

Krishnan, K. R. R., Hays, J. C., Tupler, L. A., George, L. K. \& Blazer, D. G. (1995). Clinical and phenomenological comparisons of late-onset and early-onset depression. American Journal of Psychiatry 152, 785-788.

Krishnan, K. R. R., Hays, J. C. \& Blazer, D. G. (1997). MRI-defined vascular depression. American Journal of Psychiatry 154, 497-501.

Kumar, A., Yousem, E., Souder, E., Miller, D., Gottlieb, G., Gur, R. \& Alavi, A. (1992). High-intensity signals in Alzheimer's disease without cerebrovascular risk factors: a magnetic resonance imaging evaluation. American Journal of Psychiatry 149, 248-250.

Kumar, A., Miller, D., Ewbank, D., Yousem, D., Newberg, A., Samuels, S., Cowell, P. \& Gottlieb, G. (1997). Quantitative anatomic measures and comorbid medical illness in late-life major depression. American Journal of Geriatric Psychiatry 5, 15-25.

Lesser, I. M., Mena, I., Boone, K.B., Miller, B. L., Mehringer, C. M. \& Wohl, M. A. (1994). Reduction of cerebral blood flow in older depressed patients. Archives of General Psychiatry 51, 677-686.

Lesser, I. M., Boone, K. B., Mehringer, C. M., Wohl, M. A., Miller, B. L. \& Berman, N. G. (1996). Cognition and white matter hyperintensities in older depressed patients. American Journal of Psychiatry 153, 1280-1287.

Luscombe, G., Brodaty, H., Anstey, K., Moore, C., Peisah, C. \& Andrews, G. (1995). The 25 year outcome of depression (Abstract). In 7th International Psychogeriatric Association Congress: Spirit in Ageing (29 October-3 November 1995, Sydney, Australia), pp. 115 .

Marshall, V. G., Bradley, W. G., Marshall, C. E., Bhoopat, T. \& Rhodes, R. H. (1988). Deep white matter infarction: correlation of MR imaging and histopathological findings. Radiology 167, $517-522$.

Mendlewicz, J. (1976). The age factor in depressive illness: some genetic considerations. Journal of Gerontology 31, 300-303.

Mendlewicz, J. \& Baron, M. (1981). Morbidity risks in subtypes of unipolar depressive illness: differences between early and lateonset forms. British Journal of Psychiatry 139, 463-466.

Murphy, E. (1983). The prognosis of depression in old age. British Journal of Psychiatry 142, 111-119.

Murphy, E., Smith, R., Lindesay, J. \& Slattery, J. (1988). Increased mortality rates in late-life depression. British Journal of Psychiatry 152, 347-353.

NIH Consensus Development Panel on Depression in Late Life (1992). Diagnosis and treatment of depression in late life. Journal of the American Medical Association 268, 1018-1024.

Noguchi, S., Murakami, K. \& Yamada, N. (1993). Apolipoprotein E genotype and Alzheimer's disease-Reply (correspondence). Lancet 342, 737.

O'Brien, J., Desmond, P., Ames, D., Schweitzer, I., Harrigan, S. \& Tress, B. (1996). A magnetic resonance imaging study of white matter lesions in depression and Alzheimer's disease. British Journal of Psychiatry 168, 477-485.

Olszewski, J. (1962). Subcortical arterosclerotic encephalopathy: 
review of the literature on the so-called Binswanger's disease and presentation of two cases. World Neurology 3, 359-375.

Pedro-Botet, J., Senti, M., Nogues, X., Rubies-Prat, J., Roquer, J., D'Olhaberriague, L. \& Olive, J. (1992). Lipoprotein and apolipoprotein profile in men with ischemic stroke: role of lipoprotein (a) triglyceride-rich lipoproteins, and apolipoprotein E polymorphism. Stroke 23, 1556-1562.

Plassman, B. L. \& Breitner, J. C. S. (1997). The genetics of dementia in late life. Psychiatric Clinics of North America 20, 59-76.

Robinson, R. G., Kubos, K. L., Starr, L. B., Rao, K. \& Price, T. R. (1984). Mood disorders in stroke patients: importance of location and lesion. Brain 107, 81-93.

Robinson, R. G., Starkstein, S. E. \& Price, T. R. (1988). Post stroke depression and lesion location. Stroke 19, 125-126.

Sakoda, S., Kuriyama, M., Osame, M., Takahashi, K. \& Yamano, T. (1994). Apolipoprotein E- $\epsilon 4$ - Reply (correspondence). Neurology 44, 2420.

Salloway, S., Malloy, P., Kohn, R., Gillard, E., Duffy, J., Rogg, J., Tung, G., Richardson, E., Thomas, C. \& Westlake, R. (1996) MRI and neuropsychological differences in early- and late-lifeonset geriatric depression. Neurology 46, 1567-1574.

Saunders, A. M., Strittmatter, W., Schmechel, D., St George-Hislopp, P. H., Pericak-Vance, M. A. \& Joo, S. H. (1993a). Association of apolipoprotein $\mathrm{E}$ allele $\epsilon 4$ with late-onset familial and sporadic Alzheimer's disease. Neurology 43, 1467-1472.

Saunders, A. M., Schmader, K., Breitner, J. C. S., Benson, M. D., Brown, W. T., Goldfarb, L., Goldgaber, D., Manwaring, M. G., Szymanski, M. H., McCown, N., Dole, K. C., Schmechel, D. E., Strittmatter, W. J., Pericak-Vance, M. A. \& Roses, A. D. (1993b). Apolipoprotein E $\epsilon 4$ allele distributions in late-onset Alzheimer's disease and in other amyloid-forming diseases. Lancet $\mathbf{3 4 2}$ 710-711.

Scheltens, Ph., Barkhof, F., Leys, D., Wolters, E. Ch., Ravid, R. \& Kamphorst, W. (1995). Histopathologic correlates of white matter changes on MRI in Alzheimer's disease and normal aging. Neurology 45, 883-888.

Selhub, J., Jacques, P. F., Wilson, R. B., Rush, D. \& Rosenberg, I. H. (1993). Vitamin status and intake as primary determinants of homocysteinemia in an elderly population. Journal of the American Medical Association 270, 2693-2698.
Selhub, J., Jacques, P. F., Bostom, A. G., D'Agostino, R. B., Wilson, P. W. F., Belanger, A. J., O'Leary, D. H., Wolf, P. A., Schaefer, E. J. \& Rosenberg, I. H. (1995). Association between plasma homocysteine concentrations and extra-cranial carotid-artery stenosis. New England Journal of Medicine 332, 286-291.

Shimano, H., Ishibashi, S., Murase, T., Gotohda, T., Yamada, N., Takaku, F. \& Ohtomo, E. (1989). Plasma apolipoproteins in patients with multi-infarct dementia. Atherosclerosis 79, 257-260.

Simpson, S., Talbot, P. R., Snowden, J. S. \& Neary, D. (1997). Subcortical vascular disease in elderly patients with treatment resistant depression. Journal of Neurology, Neurosurgery and Psychiatry 62, 196-197.

Skoog, I., Lernfelt, B., Landahl, S., Palmertz, B., Andreasson, L. A., Nolsson, L., Persson, G., Oden, A. \& Svanborg, A. (1996). 15-year longitudinal study of blood pressure and dementia. Lancet 347, 1141-1145.

Ueland, P. M., Refsum, H. \& Brattstrom, L. (1992). Plasma homocysteine and cardiovascular disease. In Atherosclerotic Cardiovascular Disease Hemostasis, and Endothelial Function (ed. R. B. J. Francis), pp. 183-236. Marcel Dekker Inc: New York

Vogel, T., Guo, N. H., Guy, R., Drezlich, N., Krutzch, H. C., Blake, D. A., Panet, A. \& Roberts, D. D. (1994). Apolipoprotein E: a potent inhibitor of endothelial and tumour cell proliferation. Journal of Cellular Biochemistry 54, 299-308.

Wang, X. L., McCredie, R. M. \& Wilcken, D. E. L. (1995). Polymorphisms of the apolipoprotein E gene and severity of coronary artery disease defined by angiography . Arteriosclerosis, Thrombosis, and Vascular Biology 15, 1030-1034.

Wilcken, D. E. L., Reddy, G. S. R. \& Gupta, V. J. (1983). Homocysteinemia, ischemic heart disease, and the carrier state for homocystinuria. Metabolism 32, 363-370.

Wilcken, D. E. L., Wang, X. L., Sim, A. S. \& McCredie, R. M (1996). Distribution in healthy and coronary populations of the methylenetetrahydrofolate reductase (MTHFR) $\mathrm{C}_{677} \mathrm{~T}$ mutation. Arteriosclerosis, Thrombosis, and Vascular Biology 16, 878-882.

Ylikoski, R., Ylikoski, A., Erkinjuntti, T., Sulkava, R., Raininko, R. \& Tilvis, R. (1993). White matter changes in healthy elderly persons correlate with attention and speed of mental processing. Archives of Neurology 50, 818-824. 